\title{
Alaninuria, Associated with Microcephaly, Dwarfism, Enamel Hypoplasia, and Diabetes Mellitus in Two Sisters
}

\author{
L. STIMMLER, N. JENSEN, and P. TOSELAND \\ From the Department of Paediatrics and Clinical Pathology, Guy's Hospital, London
}

Stimmler, L., Jensen, N., and Toseland, P. (1970). Archives of Disease in Childhood, 45, 682. Alaninuria, associated with microcephaly, dwarfism, enamel hypoplasia, and diabetes mellitus in two sisters. Two sisters, both microcephalic at birth and of low birthweight, are described. They are both severely mentally retarded and dwarfed, and have developed diabetes mellitus. Their teeth show enamel hypoplasia. Excessive quantities of alanine were found in their urine, which was associated with high levels of alanine pyruvate and lactate in the blood.

This report describes the biochemical findings in two sisters, who were both microcephalic since birth, dwarfed, and subsequently diabetic.

\section{Case Reports}

Case 1. This girl was born in 1963 at term, mother's pregnancy having been normal, birthweight $1.95 \mathrm{~kg}$. She was microcephalic, with head circumference $30 \mathrm{~cm}$. Her subsequent development, both physical and mental, was very retarded and she has remained dwarfed. At the age of 26 months, she was admitted to hospital in diabetic pre-coma, her blood sugar at that time being $1015 \mathrm{mg}$./ $100 \mathrm{ml}$. She was rapidly stabilized on insulin, and at present requires 24 units per day. On physical examination (Fig. 1) at the age of 5 years 5 months, she was dwarfed (length $96 \mathrm{~cm}$., weight $14.3 \mathrm{~kg}$.). She was microcephalic (head circumference $41 \mathrm{~cm}$.). Her teeth were very small, widely spaced, and showed conspicuous enamel hypoplasia (Fig. 3a). She was severely mentally retarded, having a performance level of about 18 months. She had an ataxic gait and her arm and hand movements were tremulous.

Case 2. This girl was born $1 \frac{1}{2}$ years after her sister, also at term, with a birthweight of $1.85 \mathrm{~kg}$. Head circumference $29 \cdot 8 \mathrm{~cm}$. Like her elder sister, both the physical and mental development remained severely retarded. At the time when her elder sister developed diabetes, this infant was 8 months old, and a glucose tolerance test gave the following results:

\begin{tabular}{lllllll}
\hline Time (min.) & 0 & 30 & 60 & 90 & 120 & 150
\end{tabular}

$\begin{array}{lllllll}\text { Blood glucose (mg./100 ml.) } & 33 & 88 & 55 & 39 & 39 & 64\end{array}$

At the age of 22 months, however, she was found to have developed glycosuria, and her blood sugar was then

Received 5 March 1970.
$328 \mathrm{mg} . / 100 \mathrm{ml}$. Her diabetes was treated with insulin and she is at present stabilized on 16 units soluble in the morning and 18 units in the evening. On examination, aged 4 years, there was an obvious similarity between her and her elder sister (Fig. 2). She was dwarfed (height $82 \mathrm{~cm}$. weight $12 \cdot 7 \mathrm{~kg}$.), and her head circumference was $44.5 \mathrm{~cm}$. Her teeth were very small, widely spaced, and also showed enamel hypoplasia (Fig. 3b). She was also severely mentally retarded, having a developmental level of about 8 months. Like Case 1 , she had a tremulous ataxia of her limbs. She is still unable to walk.

\section{Investigations}

Routine haematology, plasma electrolytes, liver function tests, and blood urea were normal in both children. Electro-encephalography showed no abnormality and electrocardiogram and electromyogram were normal in Case 2.

Urinary amino acids. Chromatography of urinary amino acids was carried out by the method of Samuels and Wood (1966) after deproteinization with picric acid. The only abnormality observed was a much raised urine alanine level in both sisters.

Case 2: (range of 4 determination) $63-115 \mu$ moles $/ \mathrm{kg}$.

Case 1: (range of 3 determination) 37-59 $\mu$ moles $/ \mathrm{kg}$.

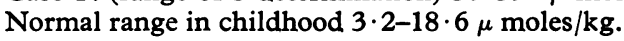

Plasma alanine levels (fasting). These were estimated by the same quantitative procedure as urinary alanine.

Case $2:-300 \mathrm{~m} \mu \mathrm{moles} / \mathrm{ml}$.

Case $1:-325 \mathrm{~m} \mu \mathrm{moles} / \mathrm{ml}$.

Normal range-210-275 $\mathrm{m} \mu$ moles $/ \mathrm{ml}$.

Glucose loads of $1 \mathrm{~g} . / \mathrm{kg}$. were given to each child and also to 6 diabetic children after an overnight fast and after their normal dose of lente insulin. In addition to 
blood glucose estimations, plasma alanine, blood pyruvate, and blood lactate levels were obtained over the same period. The blood pyruvate was measured by the enzymatic method of Gloster and Harris (1962) and the lactate also by an enzymatic technique described by Hohorst (1965).

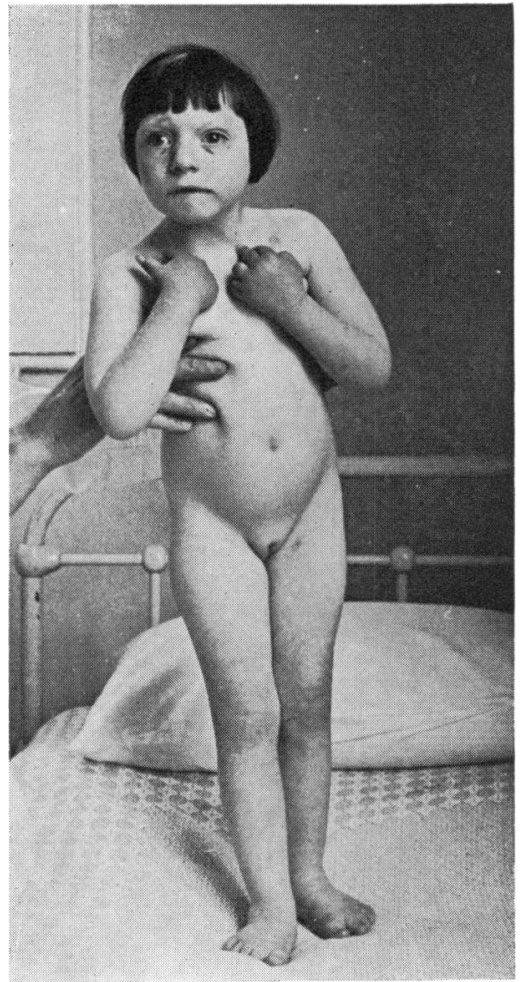

FIG. 1.-Case 1, aged 5.

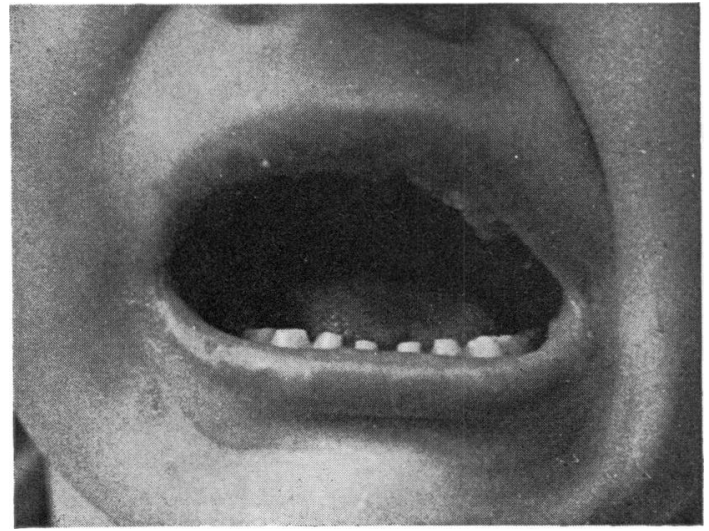

Frg. 3a.-Appearance of teeth in Case 1.
The results of this test are given in Fig. 4, 5, and 6. The fasting plasma alanine levels in Cases 1 and 2 were well outside the range of the diabetic group, and blood pyruvate and lactate were outside the range of diabetic and non-diabetic control groups. After glucose administration, plasma alanine rose $50 \mathrm{~m} \mu$ moles $/ \mathrm{ml}$., whereas there was an initial fall followed by a slight rise of $15 \mathrm{~m} \mu$ moles $/ \mathrm{ml}$. in the diabetic groups. The blood pyruvate and lactate levels rose to 3 to 4 times the fasting levels in the patients, but the rises were limited to approximately $60 \%$ in the normal control and diabetic groups.

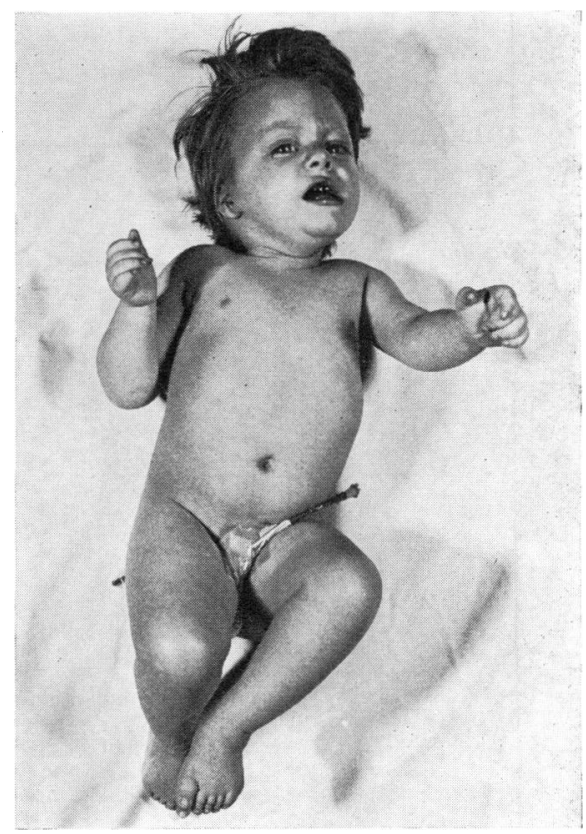

Fig. 2.-Case 2, aged 3.

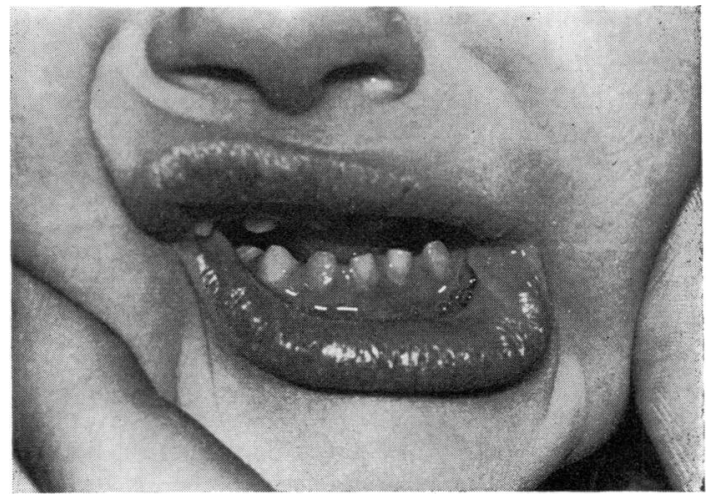

FIG. 3b.-Appearance of teeth in Case 2. 


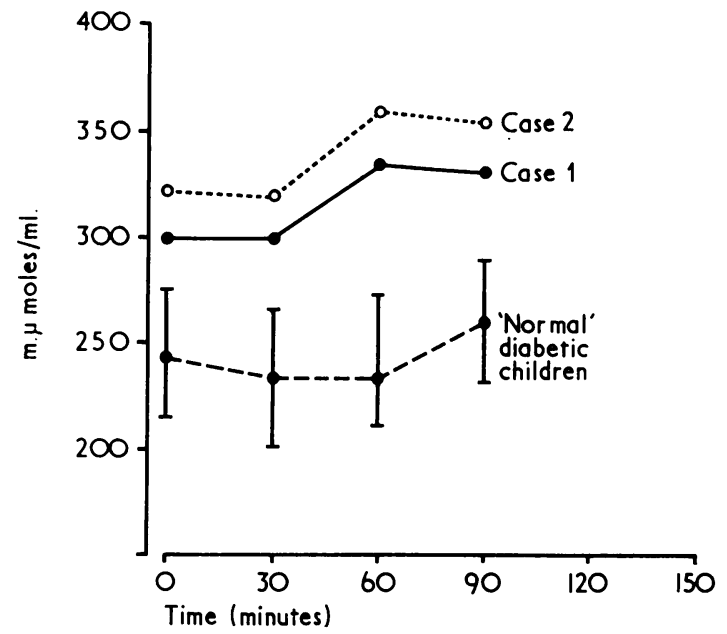

FIG. 4.-Plasma alanine levels after a glucose load of $1 \mathrm{~g} . / \mathrm{kg}$. bodyweight. Vertical bars $\pm 2 S D$.

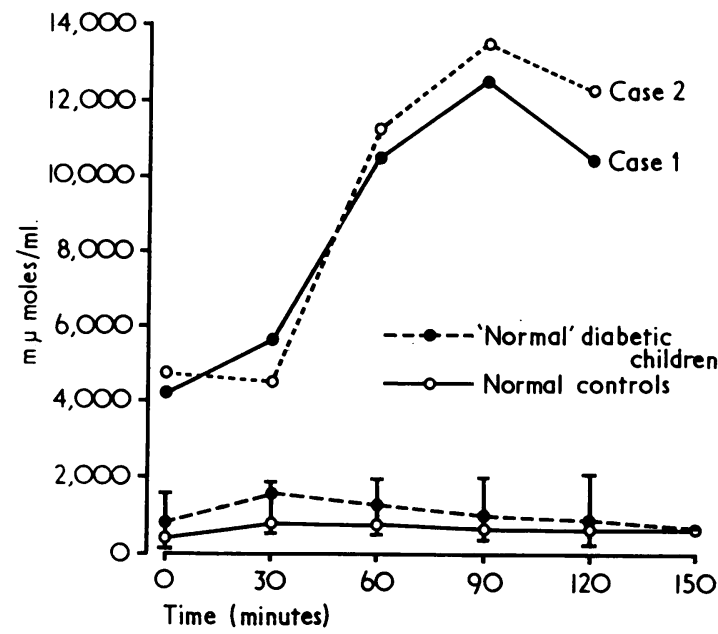

FIG. 6.-Blood lactate levels after glucose load of $1 \mathrm{~g} . / \mathrm{kg}$ bodyweight. Vertical bars, range of lactate levels for normal controls.

\section{Discussion}

Microcephaly, dwarfism, diabetes, and enamel hypoplasia have all been shown individually to be due to genetic factors (McKusick, 1966). In each case the precise metabolic cause is not known. In these two sisters, this association of apparently diverse abnormalities could conceivably be due to the mutual inheritance of a number of genes, if these are closely linked on the same chromosome, but it is also possible that all the abnormalities in these

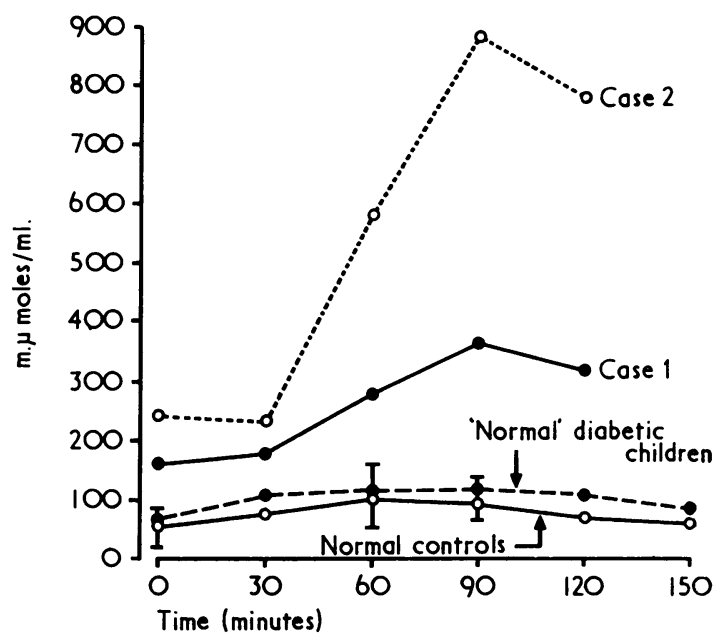

FIG. 5.-Blood pyruvate levels following glucose load of $1 \mathrm{~g} . / \mathrm{kg}$. bodyweight. Vertical bars $\pm 2 S D$ for the normal controls.

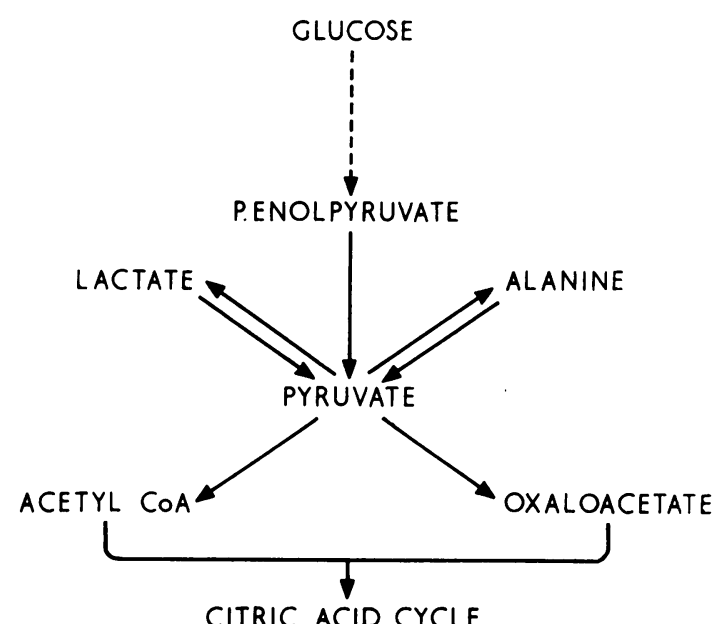

Fig. 7.-Metabolic pathways illustrating the relation between lactate, alanine, and pyruvate.

children are due to the inheritance of a single gene. If this is so, this metabolic abnormality must be manifest during fetal life to account for the dwarfism and microcephaly at birth.

The initial screening procedure showed high levels of alanine in the urine. Blood alanine levels were also raised, though not to the same degree. Alanine is, in part at least, synthesized from pyruvic acid (Fig. 7). This appears to be the most likely source of the raised alanine in these cases, 
because not only was the fasting blood pyruvate level grossly raised, but an oral glucose load in both these children resulted in a sharp rise in both blood alanine and blood pyruvate. The raised lactate levels after glucose ingestion were also probably related to the raised blood pyruvate. The cause of the raised blood pyruvate levels has not been ascertained; it is possible that it could be due to a block in pyruvate metabolism to acetyl-co enzyme $A$, or alternatively to excessive synthesis of pyruvate from glucose, particularly after a glucose load. Abnormalities of pyruvate metabolism have also been noted to a very much smaller extent in a diabetic patient by Thompson, Butterfield, and Fry (1960). The 'normal' diabetic children included in this study also showed higher levels than the laboratory 'controls', but nowhere near the levels found in Cases 1 and 2.

At least two syndromes have been described which are accompanied by raised serum lactate and pyruvate levels. In the first (Hartmann et al., 1962; Haworth, Ford, and Younoszai, 1967), symptoms first occur in the first few months of life. These infants presented with periodic episodes of metabolic acidosis associated with hyperventilation. Haworth's cases were of normal length for their age, and head circumference within normal range. Neither group of authors observed the effect of a glucose load on lactate or pyruvate levels, but Hartmann et al. showed moderate rises (30\%) in both lactate and pyruvate on administration of adrenaline, glucagon, and galactose separately on different occasions. With each test there was an associated rise of blood glucose.

In the second syndrome described by Worsley et al., 1965; Clayton, Dobbs, and Patrick, 1967; Hommes, Polman, and Reerink, 1968), the children appear to be normal at birth, but between 6 months to 1 year of age, they show progressive mental deterioration associated with ataxia. Episodes of hyperventilation also occur. The cerebral histological features in one of these cases was similar to the necrotizing encephalopathy first described by Leigh (1951). The patient described by Hommes et al. (1968) had a glucose tolerance test which did not effect the raised pyruvate and lactate levels.

In both these syndromes, in addition to raised lactate and pyruvate levels, plasma chloride was also high, suggesting that the acidosis in these children was not entirely due to the lactic or pyruvic acidosis. Excessive alaninuria was not seen in any of these children. Apart from severe mental retardation, the patients described in this paper bear little clinical resemblance to either the Hartmann or Worsley type syndromes. It seems likely, therefore, that raised levels of lactate or pyruvate account for only a proportion of the clinical manifestations of each of these syndromes. It is also probable that there is an underlying defect different in each group, but resulting in the accumulation of pyruvic and lactic acid; and in our two patients, alaninuria and diabetes mellitus.

I would like to thank Dr. R. C. Mac Keith and Dr. R. H. Rosenberg for allowing us to study these patients.

\section{REFERENCES}

Clayton, B. E., Dobbs, R. H., and Patrick, A. D. (1967). Leigh's subacute necrotizing encephalopathy: clinical and biochemical study, with special reference to therapy with lipoate. Archives of Disease in Childhood, 42, 467.

Gloster, J. A., and Harris, P. (1962). Observations on an enzymatic method for the estimation of pyruvate in blood. Clinica Chimica Acta, 7, 206.

Hartmann, A. F., Sr., Wohltmann, H. J., Purkerson, M. L., and Wesley, M. E. (1962). Lactate metabolism: studies of a child with a serious congenital deviation. Fournal of Pediatrics, 61, 165.

Haworth, J. C., Ford, J. D., and Younoszai, M. K. (1967). Familial chronic acidosis due to an error in lactate and pyruvate metabolism. Canadian Medical Association fournal, 97, 773.

Hohorst, H. J. (1965). In Methods of Enzymatic Analysis, p. 266, by N. V. Bergmeyer. Verlag Chemie, Academic Press, New York.

Hommes, F. A., Polman, H. A., and Reerink, J. D. (1968). Leigh's encephalomyelopathy: an inborn error of gluconeogenesis. Archives of Disease in Childhood, 43, 423.

Leigh, D. (1951). Subacute necrotizing encephalomyelopathy in an infant. Fournal of Neurology, Neurosurgery and Psychiatry, 14, 216.

McKusick, V. A. (1966). Mendelian Inheritance in Man: Catalogs of Autosomal Dominant, Autosomal Recessive and $X$-Linked Phenotypes, nos. 2343, 1244, 2140. Heinemann, London.

Samuels, S., and Wood, S. S. (1966). Aminoaciduria screening by thin-layer high-voltage electrophoresis and chromatography on microplates. Fournal of Laboratory and Clinical Medicine, $67,669$.

Thompson, R. H. S., Butterfield, W. J. H., and Fry, I. K. (1960). Pyruvate metabolism in diabetic neuropathy. Proceedings of the Royal Society of Medicine, 53, 143.

Worsley, H. E., Brookfield, R. W., Elwood, J. S., Noble, R. L., and Taylor, W. H. (1965). Lactic acidosis with necrotizing encephalopathy in two sibs. Archives of Disease in Childhood, 40, 492.

Correspondence to Dr. L. Stimmler, Guy's Hospital, London S.E.1. 